\title{
Arqueologia do Leste de
Mato Grosso do Sul
}

Emília Mariko Kashimoto*

Gilson Rodolfo Martins**

Este artigo apresenta os resultados advindos dos projetos de pesquisa arqueológica desenvolvidos na bacia hidrográfica do rio Paraná, Estado de Mato Grosso do Sul, Brasil. As análises abrangem variáveis ambientais indicativas da implantação de sítios arqueológicos, a cultura material e a correlação entre arqueologia e geocronologia: de grupos caçadores-coletores (11.000 anos antes do presente) aos índios ceramistas (desde pelo menos 1.500 anos antes do presente).

Palavras-chave: Arqueologia da bacia hidrográfica do rio Paraná. Caçadores-coletores. Povos indígenas ceramistas.

This article shows the results originating from the Archaeological Projects developed in hydrological basin of the Paraná river, State of Mato Grosso do Sul, Brazil. The analysis evokes the environmental variables related to the implantation of archaeological sites, the material culture and the correlation between archaeology and geochronology: from groups of huntinggathering $(11,000$ years B.P.) to the indigenous ceramists (at least 1,500 years B.P.).

Keywords: Archaeology of hydrological basin of the Paraná river. Hunting-gathering. Indigenous ceramists

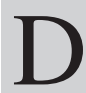
renado pelo alto curso do rio Paraná e afluentes, o contexto leste do estado integra o segmento setentrional da bacia Platina. É composto pelo ambiente de Cerrado, entre os municípios de Campo Grande e Chapadão do Sul/ Paranaíba, assim como pela Floresta Estacional Semidecidual aluvial ao longo dos terraços marginais do rio Paraná.

A descaracterização desses ambientes é marcante na atualidade, em decorrência da expansão da agropecuária, que suprimiu grande parte dessas coberturas vegetais, assim como pela formação de reservatórios de usinas hidrelétricas, os quais inundaram extensas áreas dos ambientes de calhas fluviais.

A margem direita do alto curso do rio Paraná, em Mato Grosso do Sul, caracterizava-se, antes de sua inundação

\footnotetext{
* Professora adjunta do DHD/CCHS/UFMS - MuArq, Livre-Docente em Arqueologia Brasileira (USP), pesquisadora bolsista do MCT/CNPq; emilia.kashimoto@pq.cnpq.br

** Professor titular em Arqueologia - DHI/CPAQ/UFMS, Diretor do MuArq/UFMS, pesquisador bolsista do MCT/CNPq; gilson.martins@pq.cnpq.br
} 
pelos reservatórios, por uma extensa planície bordeada por terraços fluviais de suaves declividades (inferiores a $2 \%$ ). Na margem esquerda desse rio, predominam elevados terraços estruturais.

Os sítios arqueológicos integram-se nessa paisagem em locais de topografia elevada e, portanto, protegidos das cheias anuais; possuem solos, em geral, férteis; estão nas proximidades aos corpos d'água (lagoas e canais fluviais) e fontes de matéria-prima lítica ou argilosa; apresentam expressiva fauna, aquática ou terrestre, e flora, propiciando, portanto, a pesca, a caça e a coleta.

O conhecimento científico relativo ao povoamento arqueológico desse contexto leste do atual território de Mato Grosso do Sul remete às referências preliminares fornecidas, por estudos pioneiros, em contextos circunvizinhos, tais como em sítios localizados nos estados do Paraná1, de São Paulo², de Goiás ${ }^{3}$ ou mesmo de Mato Grosso do $\mathrm{Sul}^{4}$.

Com exceção do registro de sítios no rio Samambaia ${ }^{5}$ (Chmyz, 1974), a extensa área situada entre os municípios de Naviraí e Paranaíba (aproximadamente $550 \mathrm{~km}$ de extensão ao longo do rio Paraná x 200 km de largura - figura 1) era, até o início década de 1990, praticamente desconhecida em relação ao seu conteúdo arqueológico.

As pesquisas arqueológicas extensivas no alto curso do rio Paraná tiveram início em 1993 e continuam até o presente, desenvolvidas pela equipe do MuArq/ UFMS, sob a coordenação de Emília M. Kashimoto e Gilson R. Martins, com apoio, principalmente, da CESP, CNPq e FUNDECT-MS (anexo 1).

Tais pesquisas foram desenvolvidas sob a perspectiva de que a frequência e a intensidade dos trabalhos de campo e de laboratório, nos quais se incluem as datações

\footnotetext{
${ }^{1}$ LAMING. A., EMPERAIRE, J. A Jazida José Vieira - um Sítio Guarani e Pré-cerâmico do Interior do Paraná. Arqueologia. Conselho de Pesquisas da Uiversidade do Paraná, n. 1, secção 1, 1959, p. 1142; BLASI, O. O Sítio Arqueológico de Estirão Comprido. Rio Ivaí - Estudos Complementares. Arquivos do Museu Paranaense. Nova Série, Arqueologia, n. 3, 1967.

${ }^{2}$ PALLESTRINI, L. Sítio Arqueológico da Lagoa São Paulo. Presidente Epitácio, SP. Revista de PréHistória. Instituto de Pré-História da USP, v. 6, 1984, p. 381-410.

${ }^{3}$ SCHMTZ, P. I. et alii. Arqueologia nos Cerrados do Brasil Central, Serranópolis I. PesquisasAntropologia. São Leopoldo, n. 44, 1989.

${ }^{4}$ CHMYZ, I. Dados Arqueológicos do Baixo Rio Paranapanema e Alto Rio Paraná. In: PRONAPA - Resultados Preliminares do 5 Ano. Belém: Museu Paraense Emilio Goeldi, Pub. Avulsas, n. 26, 1974.
}

${ }^{5}$ Idem. 
radiométricas ${ }^{6}$, subsidiam a construção de um circunstanciado banco de dados para, a partir da freqüência dos resultados, se estabelecer interpretações efetivas acerca dos panoramas culturais pré-históricos no Alto Paraná. Considera-se que a pesquisa pré-histórica em áreas cujo conhecimento arqueológico disponível é insuficiente face à sua extensão espacial, pressupõe a necessidade dessa análise circunstancia-

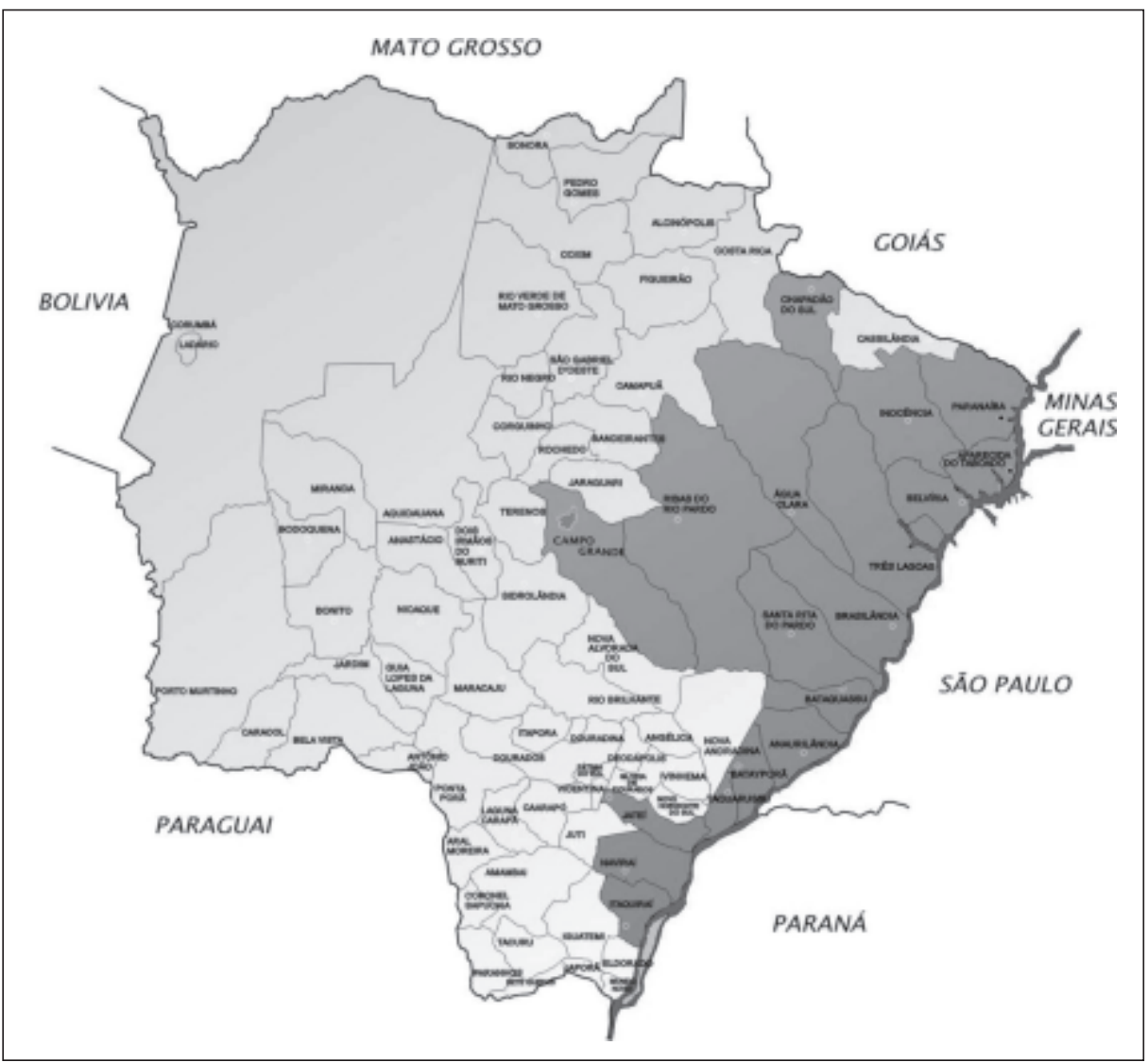

Figura 1: municípios drenados pela margem direita do rio Paraná e afluentes, enfocados nesta pesquisa.

\footnotetext{
${ }^{6}$ As datações por termoluminescência foram realizadas no Laboratório de Vidros e Datação da Faculdade de Tecnologia de São Paulo, sob a coordenação da Profa. Dra. Sonia Hatsue Tatumi; As datações calibradas de amostras de carvões de fogueiras, pelo método do carbono 14, foram realizadas em dois laboratórios: no Laboratoire des Sciences du Climat et de l'Environnement - Laboratoire Mixte CEA-CNRS UMR 1572, em Gif-sur-Yvette/França, sob a responsabilidade do Dr. Michel Fontugne, e no Beta Analytic Inc., Miami/Florida, sob a responsabilidade do Dr. Darden Hood.
} 
da e a consolidação de uma abordagem histórico-cultural que substancie a realização de análises posteriores acerca dos processos culturais pré-históricos regionais.

Dessa forma, ao longo dos últimos 16 anos de trabalhos, essas pesquisas arqueológicas na margem direita do rio Paraná e no baixo curso de seus afluentes já abrangeram segmentos dos municípios de Itaquiraí, Naviraí, Jateí, Bataiporã, Anaurilândia, Bataguassu, Santa Rita do Pardo, Brasilândia, Três Lagoas, Selvíria e Aparecida do Taboado, localizando-se, até o momento, um total de 199 sítios arqueológicos a céu aberto, remanescentes de aldeias ou acampamentos de povos agricultores ceramistas, e/ou de acampamentos de caçadores-coletores-pescadores pré-históricos em áreas de afloramentos de cascalheiras fluviais. Nos municípios de Paranaíba e Aparecida do Taboado, a pesquisa se estendeu ao rio Paranaíba que, após sua confluência com o rio Grande, forma o rio Paraná. No rio Paranaíba foram localizados 16 sítios arqueológicos, predominantemente acampamentos líticos em áreas de afloramento de blocos de arenito silicificado.

Atualmente encontra-se em desenvolvimento o projeto Levantamento arqueológico sistemático ao longo das estradas da porção setentrional do Planalto sul-mato-grossense: contribuição à arqueologia da Bacia do Paraná (Processo CNPq nº. 400.555/2007-7), o qual resultou na localização de 15 sítios arqueológico nos cursos médio e superior dos afluentes do rio Paraná. Dessa forrma, totaliza-se a localização de 232 sítios arqueológicos na margem direita do rio Paraná e afluentes em MS, conforme se apresenta na tabela 1.

Os procedimentos de pesquisa já realizados nos sítios situados na margem direita do rio Paraná e afluentes, totalizam escavações de 36 sítios arqueológicos e datações de 174 amostras, compostas por fragmentos de cerâmica ou de carvão, além de coleta de cerca de 70.000 peças arqueológicas. Os dados obtidos nessas pesquisas evidenciaram o panorama de ocupação arqueológica da área: desde os povos caçadores-coletores-pescadores ${ }^{7}$, de cerca de 6.000 anos A.P., até os agricultores ceramistas Guarani do século XVII.

Esse intenso povoamento da planície e terraços fluviais do rio Paraná também se estendia aos altos terraços estruturais de sua margem esquerda, estado de

\footnotetext{
${ }^{7}$ Os sítios arqueológicos localizados no alto curso do rio Paraná situam-se, em sua maioria, nas bordas de terraços e diques marginais dos canais fluviais, portanto diretamente voltados para esses canais. O material lítico encontrado nesses sítios sugere sua utilidade à pesca. Dessa forma, utilizase nesta pesquisa a denominação "caçadores-coletores-pescadores".
} 
São Paulo, onde já foram localizados 134 sítios arqueológicos ${ }^{8}$. Dessa forma, em ambas as margens desse alto curso do rio Paraná (estados de Mato Grosso do Sul e São Paulo) já foram localizados 333 sítios arqueológicos testemunhando a intensidade do povoamento pretérito regional (figura 2).

Considerando-se a estreita relação entre culturas pretéritas e ambientes, apresenta-se, a seguir, uma síntese preliminar acerca de características paleoambientais e o povoamento arqueológico, desse contexto leste de MS, por povos caçadores-coletores-pescadores pré-históricos e por povos agricultores ceramistas pré-coloniais.

Tabela 1: Inserção municipal dos 232 sítios arqueológicos localizados na margem direita do rio Paraná e afluentes em MS.

\begin{tabular}{|c|c|c|c|c|}
\hline \multirow[t]{2}{*}{ MUNICÍPIO DE MS } & \multicolumn{3}{|c|}{ TOTAL DE SÍTIOS ARQUEOLÓGICOS } & \multirow{2}{*}{$\begin{array}{c}\text { RESULTADOS DE } \\
\text { DATAÇÕES } \\
\text { (anos antes do presente) }\end{array}$} \\
\hline & $\begin{array}{c}\text { rio } \\
\text { Paraná }\end{array}$ & $\begin{array}{l}\text { cursos médio e } \\
\text { superior de afluentes }\end{array}$ & $\begin{array}{c}\text { rio } \\
\text { Paranaíba }\end{array}$ & \\
\hline Itaquiraí & 199 & - & - & $480 \pm 30$ \\
\hline Navirai & & - & - & $220 \pm 15$ a $600 \pm 57$ \\
\hline Jateí & & - & - & - \\
\hline Bataiporã & & - & - & $180 \pm 20$ a $6.090 \pm 60$ \\
\hline Anaurilândia & & 1 & - & $350 \pm 40$ a $4.230 \pm 75$ \\
\hline Bataguassu & & - & - & $240 \pm 30$ a $2.640 \pm 65$ \\
\hline Santa Rita do Pardo & & - & - & $275 \pm 20$ a $1.860 \pm 45$ \\
\hline Brasilândia & & - & - & $245 \pm 15$ a $5.910 \pm 70$ \\
\hline Três Lagoas & & 2 & - & $350 \pm 35$ a $6.020 \pm 60$ \\
\hline Selvíria & & - & - & - \\
\hline Aparecida do Taboado & & 4 & 5 & - \\
\hline Paranaíba & - & 4 & 11 & - \\
\hline Paraíso & - & 1 & - & - \\
\hline Água Clara & - & 3 & - & - \\
\hline Ribas do Rio Pardo & - & 1 & - & - \\
\hline Campo Grande & - & 1 & - & - \\
\hline
\end{tabular}

${ }^{8}$ KUNZLI, R. Relação de Sítios Arqueológicos Localizados no Projeto de Arqueologia da Margem Esquerda do Rio Paraná, Área da usina Hidrelétrica Sergio Motta. Presidente Prudente: FCT/UNESP, s/d (não publicado). 


\section{Sítios Arqueológicos no Alto Paraná}

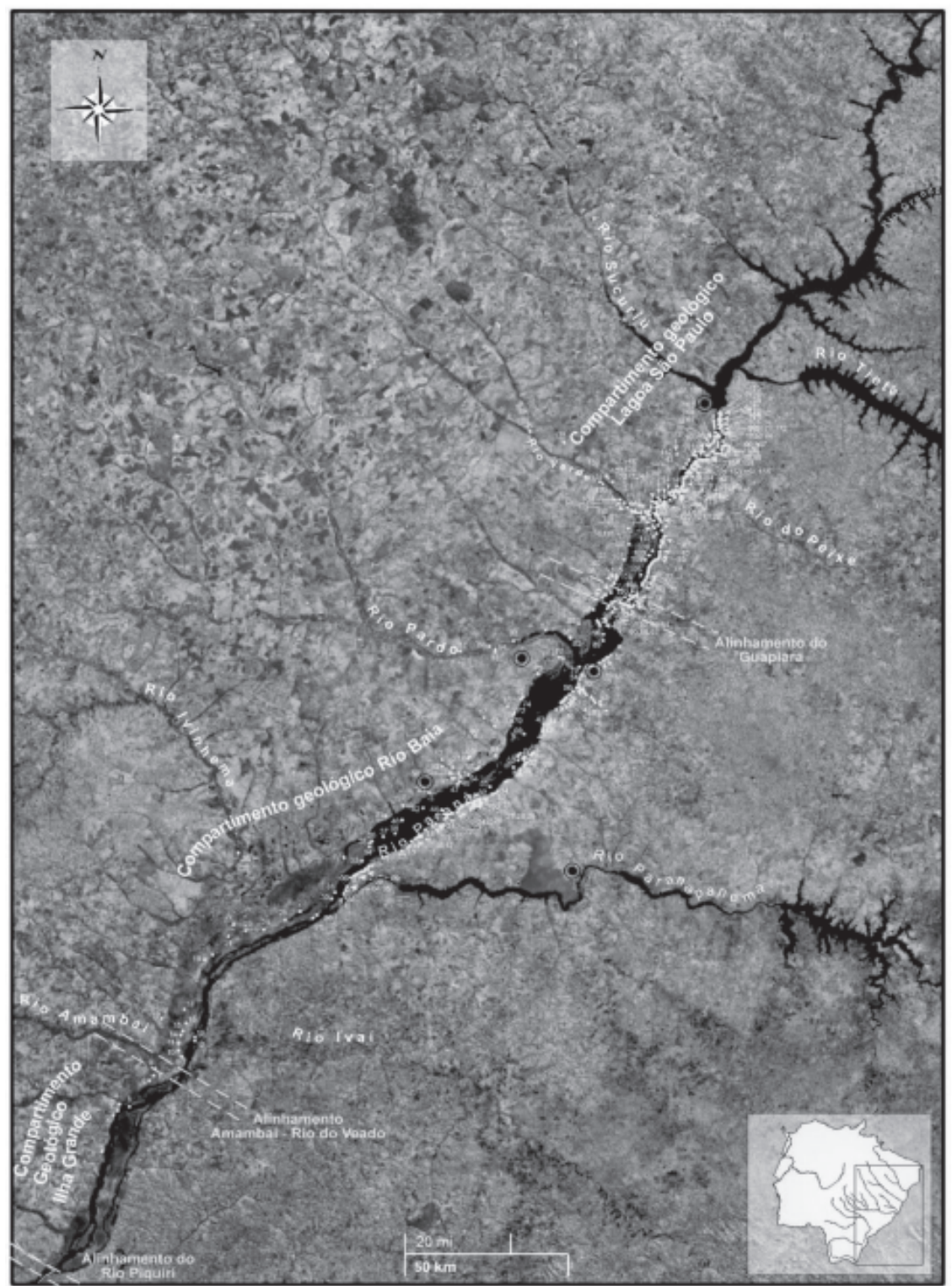

Fontes: Chmyz, 197

Kashimoto e Martins, 2004

Figura 2: sítios arqueológicos (sinalizados por pontos amarelos) localizados nas margens direita e esquerda do rio Paraná, remanescentes à formação do reservatório da UHE Sérgio Motta (Porto Primavera). 


\section{Eventos paleoclimáticos e periodização preliminar da argueologia do Alto Curso do Rio Paraná}

Como em outros estados brasileiros, em Mato Grosso do Sul o povoamento humano teve sua origem muitos séculos antes do início da colonização européia. Nesse contexto, na porção setentrional da bacia do Paraná, em Mato Grosso do Sul, esse povoamento abrangeu dois extensos compartimentos cronológicos/culturais (tabela 2).

Tabela 2: Compartimentos cronológicos/culturais na porção setentrional da bacia do Paraná em MS.

\begin{tabular}{|c|c|c|}
\hline $\begin{array}{l}\text { COMPARTIMENTOS } \\
\text { CRONOLÓGICOS/ } \\
\text { CULTURAIS }\end{array}$ & ÁREA & SÍTIOS DATADOS \\
\hline \multirow[t]{2}{*}{$\begin{array}{l}\text { Final do Pleistoceno/ } \\
\text { primeira metade do } \\
\text { Holoceno (período ar- } \\
\text { caico ou pré-histórico) }\end{array}$} & $\begin{array}{l}\text { Alto curso do rio Sucuriú } \\
\text { (afluente da margem di- } \\
\text { reita do rio Paraná). Síti- } \\
\text { os em abrigos sob rocha } \\
\text { com arte rupestre e in- } \\
\text { dústria lítica sobre blo- } \\
\text { cos e seixos. }\end{array}$ & $\begin{array}{l}\text { - MS.PA.2 "Casa de Pedra", ocupado por } \\
\text { caçadores-coletores há 10.480 } \pm \mathbf{7 0} \text { anos A.P. } \\
\text { (Silva et al., 1986; Veroneze, 1994). Integra } \\
\text { o município de Paraíso das Águas/MS. } \\
\text { - sítio Alto Sucuriú 4, ocupado por caçado- } \\
\text { res-coletores há cerca de 11.230 anos A.P. } \\
\text { (Martins e Kashimoto, 2008). Integra o mu- } \\
\text { nicípio de Água Clara/MS. }\end{array}$ \\
\hline & $\begin{array}{l}\text { Margem do rio Paraná. } \\
\text { Sítios a céu aberto com } \\
\text { indústria lítica sobre sei- } \\
\text { xo }\end{array}$ & $\begin{array}{l}\text { - sítio Rio Baía 1, ocupado por caçadores- } \\
\text { coletores-pescadores há cerca de } \mathbf{6 . 0 9 0} \pm \\
\mathbf{6 0} \text { anos A.P. Integra o município de } \\
\text { Bataiporã/MS } \\
\text { - sítio Brasilândia } 8 \text {, ocupado por caçado- } \\
\text { res-coletores-pescadores há cerca de } \mathbf{5 . 9 1 0} \\
\pm \mathbf{7 0} \text { anos A.P. Integra o município de } \\
\text { Brasilândia/MS. } \\
\text { - Sítio Ilha Comprida 10, ocupado por ca- } \\
\text { çadores-coletores-pescadores, há cerca de } \\
\mathbf{6 . 0 2 0} \pm \mathbf{6 0} \text { anos A.P. Integra o município } \\
\text { de Três Lagoas/MS }\end{array}$ \\
\hline $\begin{array}{l}\text { Segunda metade do Holo- } \\
\text { ceno (formativo/ clássico } \\
\text { das culturas indígenas } \\
\text { ceramistas pré-coloniaise } \\
\text { pós-descobrimento). }\end{array}$ & $\begin{array}{l}\text { Margem do rio Paraná. } \\
\text { Sítios a céu aberto com } \\
\text { indústria scerâmica e } \\
\text { lítica (sobre seixo) }\end{array}$ & $\begin{array}{l}\text { - datações: entre } \mathbf{1 3 8 0} \pm \mathbf{7 0} \text { anos A.P. e } 220 \pm \\
15 \text { anos A.P., em sua maioria sítios tupiguarani. } \\
\text { Municípios: Itaquiraí, Naviraí, Jateí, } \\
\text { Bataiporã, Anaurilândia, Bataguassu, Santa } \\
\text { Rita do Pardo, Brasilândia, Três Lagoas. }\end{array}$ \\
\hline
\end{tabular}


Os paleoclimas do Pleistoceno superior ao Holoceno, no alto curso do rio Paraná, foram identificados por Stevaux ${ }^{9}$ : primeira fase mais seca (idade superior a 40.000 até cerca de 20.000 anos A.P), primeira fase mais úmida (8.000 a 3.500 anos A.P.), segunda fase mais seca (3.500 a 1.500 anos A.P.), segunda fase mais úmida (1.500 anos A.P. até a atualidade).

Até o presente estágio das pesquisas arqueológicas não foram encontrados, portanto, vestígios humanos correlatos ao primeiro evento paleoclimático (primeira fase mais seca). Dessa forma, o povoamento humano conhecido iniciou-se a partir da transição Pleistoceno/Holoceno, conforme testemunham os vestígios arqueológicos de acampamentos em abrigos sob rocha.

O povoamento do ambiente de calha do alto curso do rio Paraná (terraços fluviais) se constituiu a partir de cerca de 6.000 anos A.P., ao longo dos três eventos paleoclimáticos subseqüentes, conforme se apresenta a seguir.

\section{1) Primeira fase mais úmida (8.000 a 3.500 anos A.P.) e o povoamento dos terraços fluviais do rio Paraná por caçadores-coletores-pescadores}

Após o final do Pleistoceno, o aumento das temperaturas e das condições de umidade atingiu um ápice por volta de 6.500 a 4.000 anos A.P., caracterizando o fenômeno ambiental conhecido como idade hipsitérmica ou "optimum climático". Esse período é caracterizado por uma expressiva expansão da cobertura vegetal e pela multiplicação da fauna terrestre de pequeno porte. A realidade arqueológica dessa época, pelo que se conhece até o momento, evidencia uma diminuição na ocupação dos abrigos sob rocha e a multiplicação de sítios arqueológicos a céu aberto.

Sob tais condições ambientais de expansão da fauna e flora, bandos de caçadores-coletores-pescadores exploraram seus territórios em deslocamentos sazonais, acampando nas margens dos corpos d'água perenes, produzindo suas ferramentas líticas sobre calhaus e seixos. Isso há pelo menos 6.000 anos atrás,

\footnotetext{
${ }^{9}$ STEVAUX, J. C. Climatic events vuring the late Pleistocene and Holocene in the Upper Paraná River: corelation with Argentina and South-Central Brazil. Quaternary International, 72:73-85, 2000 .
} 


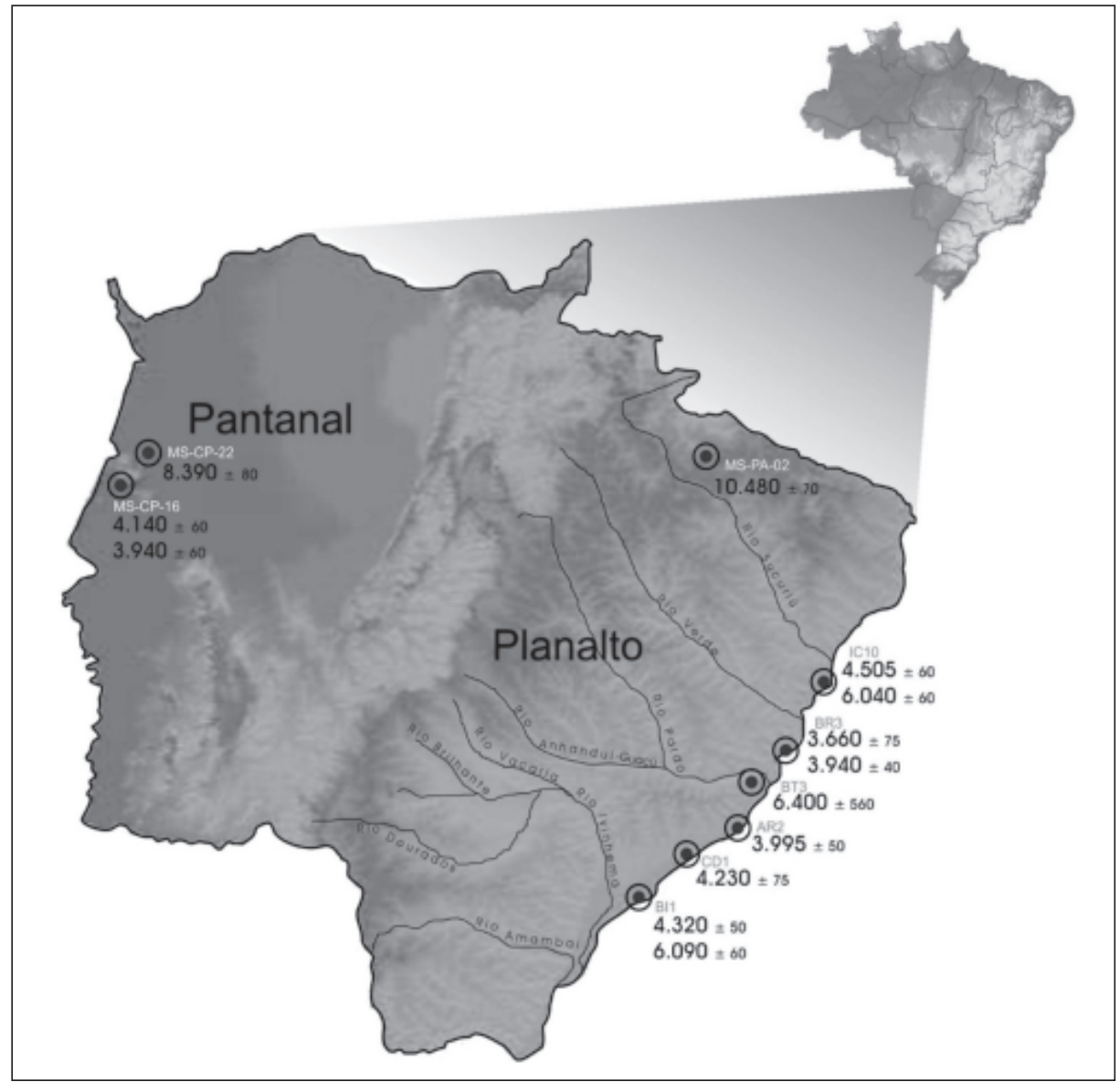

Figura 3: mapa das datações mais antigas já obtidas de Mato Grosso do Sul.

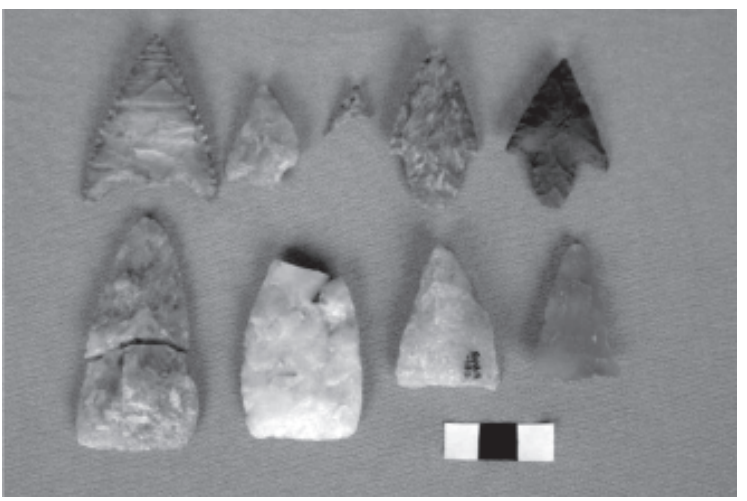

Figura 4: Pontas líticas de caçadores-coletores-pescadores do alto curso do rio Paraná (no alinhamento superior, da esquerda para a direita, 3 pontas do sítio CD1 e 2 do BR8; no alinhamento inferior, da esquerda para a direita, 2 pontas do BR8, uma do CD1 e uma do BI1). 


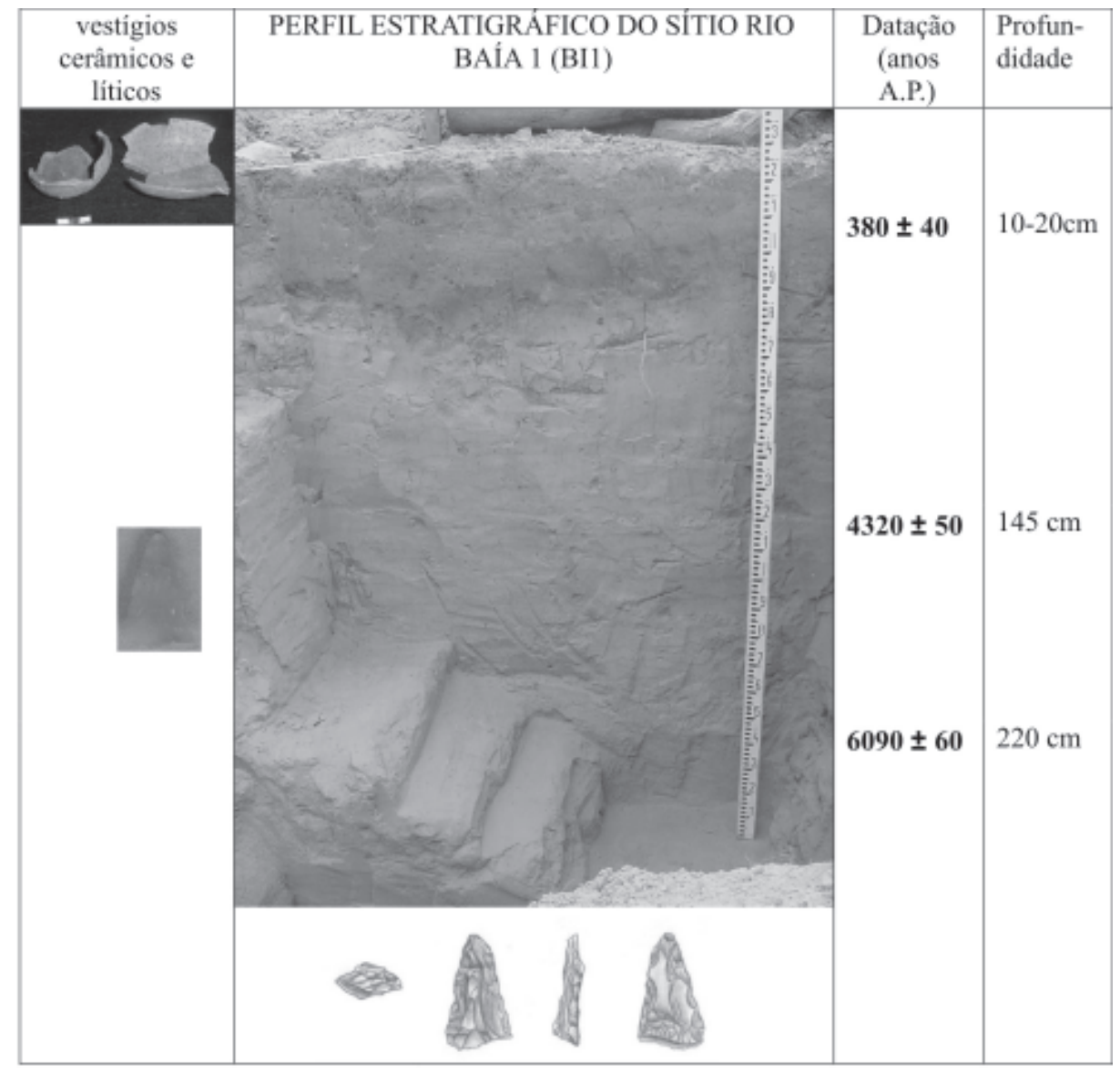

Figura 5: Sítio Rio Baía 1 - perfil estratigráfico, com destaque para os dois horizontes marcados, respectivamente, pela cerâmica guarani, e pela ponta lítica de caçadores-coletores-pescadores

conforme os dados obtidos nas escavações dos sítios Rio Baía 1 (BI1), Brasilândia 8 (BR8) e Ilha Comprida 10 (IC10), respectivamente na área municipal de Bataiporã, Braslândia e Três Lagoas/MS, conforme se localiza nas figuras 3, 4 e 5.

As ocupações nos sítio BI1 e CD1 são correlacionadas à caçadores-coletores da tradição Umbu, que acamparam em locais protegidos da inundação, próximos aos cursos d'água, com fontes de matéria-prima lítica apta ao lascamento. 


\section{2.) Segunda fase mais seca (3.500 a 1.500 anos A.P.): caçadores-coletores ou agricultores?}

Sob condições locais de uma segunda fase mais seca, estabelecida há aproximadamente 3.500 e 1.500 anos atrás, observa-se que:

- o menor volume d'água nos tributários do Alto Paraná, provavelmente aumentava a atração da fauna terrestre para a margem desse grande rio, onde se encontravam também frutos, além dos peixes. Os habitantes pré-históricos do Alto Paraná, atraídos aos locais portadores de expressivos recursos alimentares, acampavam nessas margens, deixando testemunhos materiais compostos líticos lascados (porém em menor densidade que naquelas ocupações datadas entre 6.000 e 4.000 anos atrás) e por carvões ou solo queimado de fogueiras, os quais reforçam a associação dessas ocupações a acampamentos ligados a atividades de pesca, caça e coleta (figura 6);

- a não identificação de vestígios cerâmicos nessas camadas arqueológicas não permite uma correlação direta das mesmas ao modo de vida agricultor. Seriam testemunhos de caçadores-coletores-pescadores, eventualmente com práticas de manejo vegetal, seriam proto-agricultores, ou mesmo agricultores não portadores de cerâmica? A continuidade das pesquisas permitirá a discussão dessa problemática. O que se tem como certo é que não correspondem às características ocupações Guarani que os sucederam no Alto Paraná, pois suas aldeias/sítios contém numerosos vestígios cerâmicos. 


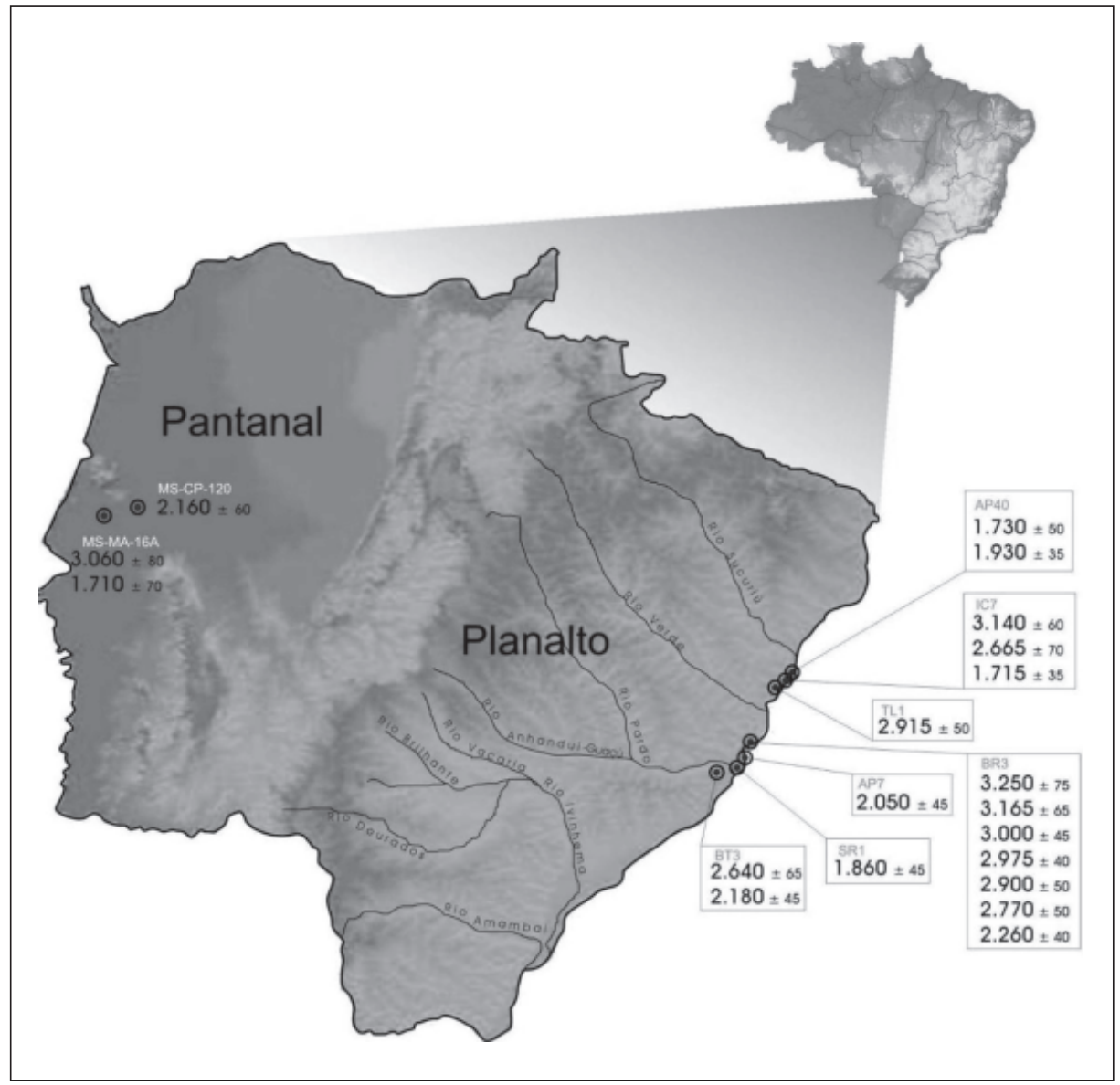

Figura 6: datações de horizontes líticos da segunda fase mais seca (3.500 a 1.500 anos A.P.)

3.) Segunda fase mais úmida (desde 1.500 anos A.P.): agricultores ceramistas tupiguarani

A partir do estabelecimento da segunda fase mais úmida, há cerca de 1.500 anos, o incremento de temperatura e umidade proporcionou o desenvolvimento da floresta aluvial atraente para a presença dos indígenas agricultores e produtores de cerâmica, na região. As datações obtidas indicam ocupações no intervalo entre $1.380 \pm 70$ (Sítio Ilha Comprida 8 - IC8) e 240 anos A.P. (sítio Bataguaçu 4 - BT4, rio Pardo). 
O ambiente florestado, amplamente desenvolvido ao sul do rio Pardo (Compartimento Rio Baía), atraiu os Guarani ceramistas que construíram grandes aldeias, preferencialmente nos terraços estruturais característicos da margem esquerda do Alto Paraná. Nos ambientes fluviais da margem direita desse alto curso, os sítios situavam-se nos diques naturais, ou seja, nas áreas menos afetadas pelas variações sazonais de nível d'agua do Alto Paraná. A baixa densidade de vestígios arqueológicos nesses locais sugere que se tratam de acampamentos de caça-pesca-coleta e/ou de cultivo, ou seja, território explorado a partir de um centro de permanência (aldeias em áreas não inundáveis), ou locais de práticas rituais (tais como de sepultamento humano - figura 7).

A densidade e variedade florística/faunística da floresta provavelmente incorporou-se à cultura material de grupos indígenas que desenvolveram técnicas e instrumentos eficazes à captação de, pelo menos, parte desses recursos alimentares, conforme já registrou a Etno-história dos povos indígenas regionais.

Os resultados indicam ocupações Guaranis coloniais na margem direita do rio Paraná, constituindo o final de uma sequiência de instalações, antecedidas por outras pré-coloniais. A maior quantidade de sítios nos afluentes do Alto Paraná, portadores de restrita variedade e densidade cerâmica, testemunha o processo de desterritorialização guarani e o findar da hegemonia indígenas no Alto Paraná.

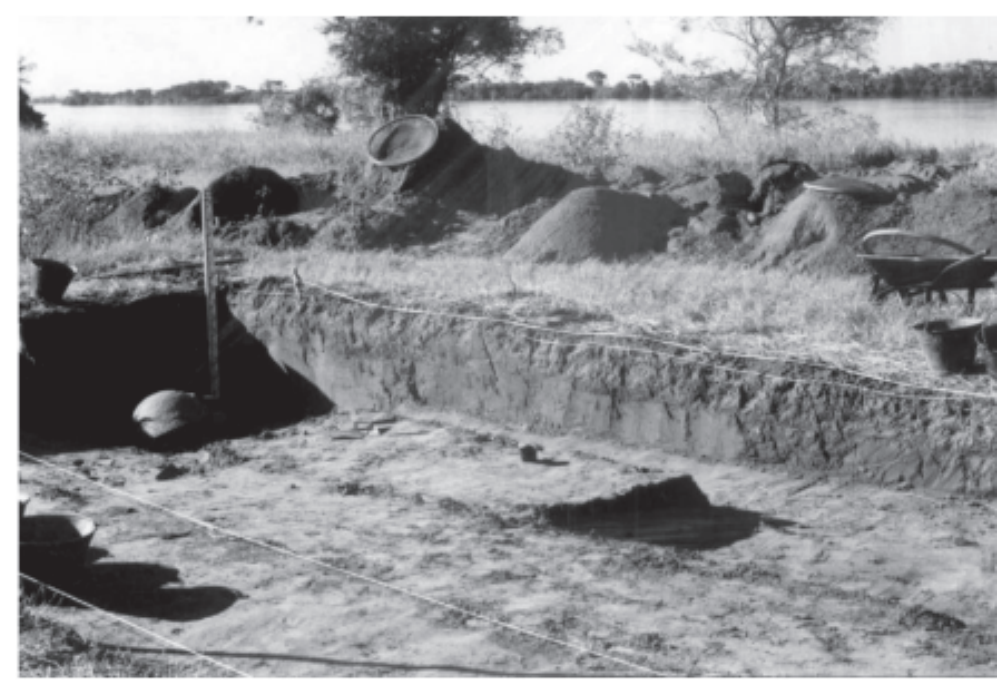

Figura 7: Escavação arqueológica do sítio Alto Paraná 8 (AP8) 


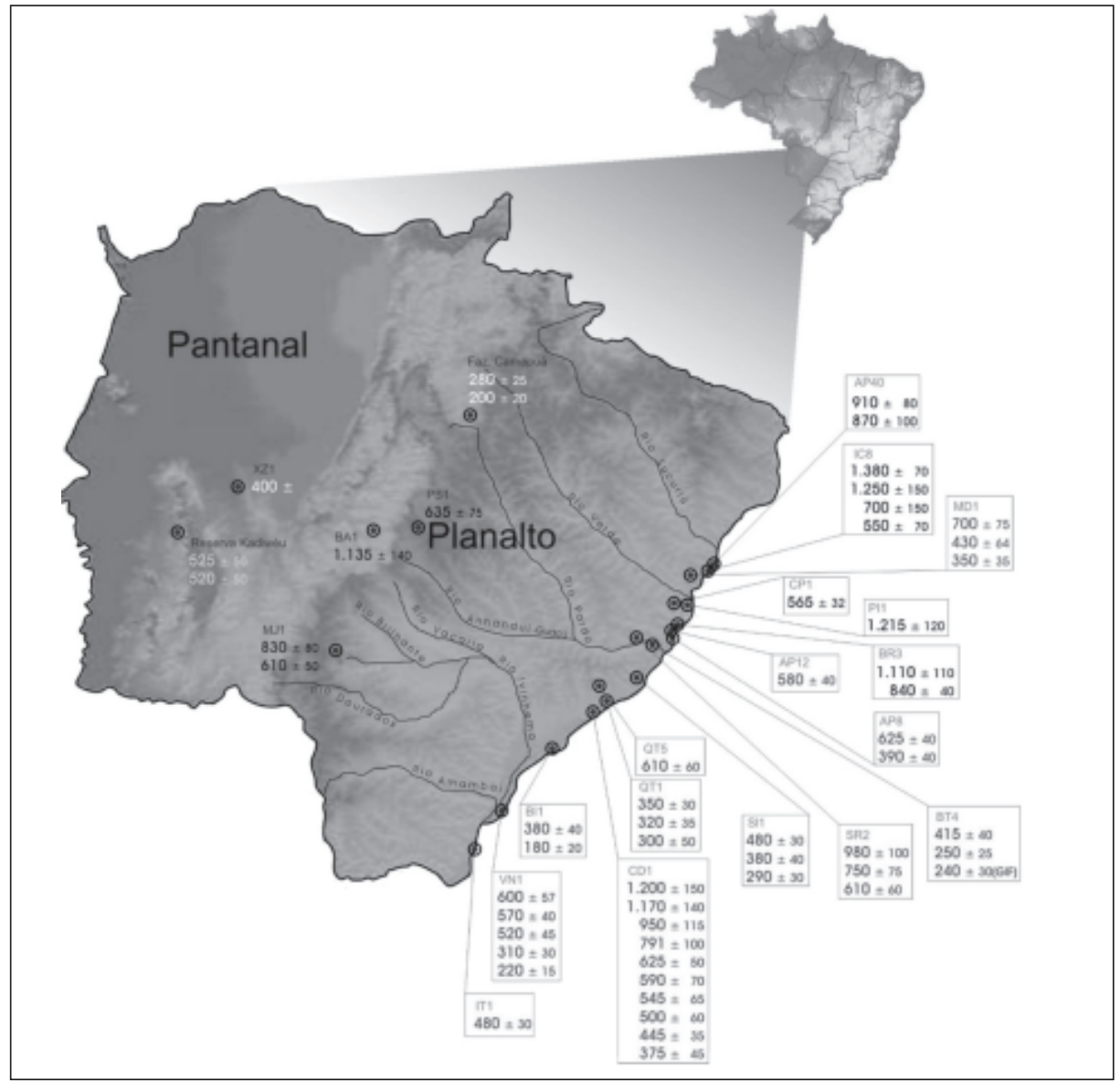

Figura 8: datações arqueológicas de ocupações tupiguarani no rio Paraná.

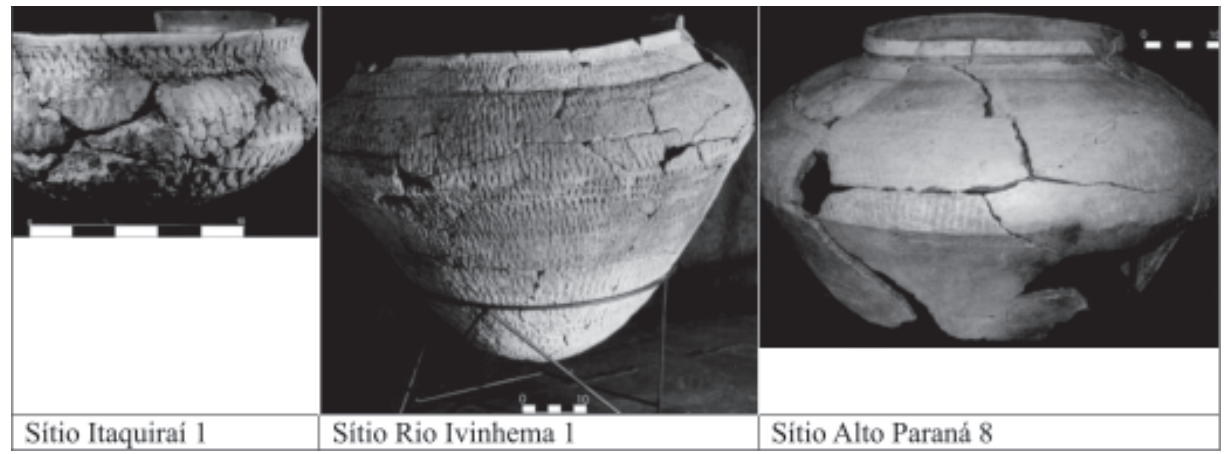

Figura 9: Vasilhas cerâmicas tupiguarani do Alto Paraná 


\section{Anexo 1}

Projetos na Bacia do Alto Paraná - Período 1988 a 2010

\section{Projetos de Pesquisa}

1.1. DISSERTAÇÃO DE MESTRADO GEOARQUEOLOGIA DO BAIXO PARANAPANEMA: SUBSÍDIOS GEOGRÁFICOS PARA A COMPREENSÃO DE ESTABELECIMENTOS HUMANOS PRÉ-HISTÓRICOS

\$ Processo: FAPESP n ${ }^{\circ}$ 88/1348-7 (bolsa de mestrado - Arqueologia/USP)

- Pesquisador: Emília M. Kashimoto - ITE

- Período da pesquisa: 1988 a 1991

1.2. PROJETO ARQUEOLÓGICO PORTO PRIMAVERA, MS - ETAPA DE LEVANTAMENTO

- Contrato: ${ }^{\circ}$ 99000-94000/0143, de 1993 - CESP/FAPEC

- Coordenação: Gilson R. Martins - UFMS/CPAQ/DHI/LPA

- Período: 1993 a 1995

1.3. PROJETO ARQUEOLÓGICO PORTO PRIMAVERA, MS - ETAPA DE RESGATE

- Contrato: ${ }^{\circ}$ MMA/CESP-FAPEC/01/97 - CESP/FAPEC

- Coordenação: Emília M. Kashimoto - Laboratório de Pesquisas Arqueológicas do Museu Dom Bosco-UCDB/MDB/LABPAR

- Período: 1997 a 1999

1.4. PROJETO LEVANTAMENTO ARQUEOLÓGICO NA ÁREA A SER DIRETAMENTE IMPACTADA PELO GASODUTO BOLÍVIA-BRASIL EM MATO GROSSO DO SUL-TRECHO TERENOS/TRÊS LAGOAS

- Contrato: PETROBRÁS/FAPEC

- Coordenação: Gilson R. Martins - UFMS

- Pesquisador adjunto: Emília M. Kashimoto - UCDB

- Período: 1993 
1.5. PROJETO PROSPECÇÃO ARQUEOLÓGICA NA ÁREA A SER DIRETAMENTE IMPACTADA PELO GASODUTO BOLÍVIA-BRASIL EM MATO GROSSO DO SUL - TRECHO TERENOS/TRÊS LAGOAS

- Contratos: PETROBRÁS/FAPEC n578-2-023-97-0/578-2-059-97-3

- Coordenação: Gilson R. Martins - UFMS

- Pesquisadora adjunta: Emília M. Kashimoto - UCDB

- Período: 1997

1.6. PROJETO RESGATE ARQUEOLÓGICO NA ÁREA A SER DIRETAMENTE IMPACTADA PELO GASODUTO BOLÍVIA-BRASIL EM MATO GROSSO DO SUL -TRECHO TERENOS/TRÊS LAGOAS

- Contrato: PETROBRÁS/FAPEC n578-3-201-97

- Coordenação: Gilson R. Martins - UFMS

- Pesquisadora adjunta: Emília M. Kashimoto - UCDB

- Período: 1997 a 1998

1.7. PROJETO ANÁLISE DE ACERVO ARQUEOLÓGICO COLETADO EM ESCAVAÇÕES REALIZADAS NA PLANÍCIE DE INUNDAÇÃO DO ALTO PARANÁ, MS

- Convênio: FUNDECT/UCDB nº 005/00

- Coordenação: Emília M. Kashimoto - UCDB/MDB/LABPAR

- Período: 03/2000 a 03/2002

1.8. PROJETO ARQUEOLOGIA DA PAISAGEM DAS VÁRZEAS DOS RIOS IVINHEMA E PARANÁ: REGISTRO E PRESERVAÇÃO DO PATRIMÔNIO CULTURAL

- Convênio: FUNDECT-CNPq/UCDB nº 015/02

- Coordenação: Emília M. Kashimoto - UCDB/MDB/LABPAR

- Período: 06/05/2002 a 05/06/2004 
1.9. PROJETO CONHECENDO E PRESERVANDO O PATRIMÔNIO ARQUEOLÓGICO LOCAL: ESCAVAÇÕES DE SÍTIOS NO CONTEXTO DAS VÁRZEAS DO RIO IVINHEMA

- Termo de Outorga: FUNDECT-CNPq/UCDB nº 098/04

- Coordenação: Emília M. Kashimoto - UCDB/UFMS

- Pesquisador adjunto: Gilson R. Martins - UFMS

- Sítios pesquisados nas proximidades da foz do rio Ivinhema: Rio Ivinhema

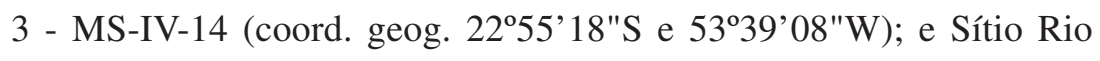

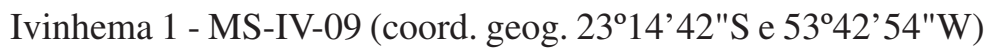

- Período: 27/07/2004 A 27/07/2006

1.10. PROJETO: ESCAVAÇÃO ARQUEOLÓGICA DO SÍTIO RIO BAÍA I: CONTRIBUIÇÃO À ANÁLISE DOS HORIZONTES PRÉ-CERÂMICOS E GUARANI DA MARGEM DIREITA DO ALTO RIO PARANÁ

- Processo: CNPq n 402224/2004-3

- Coordenação: Emília M. Kashimoto - UFMS

- Pesquisador adjunto: Gilson R. Martins - UFMS

- Sítio pesquisado: Rio Baía 1 (coord. geog. 2241’39"S 53¹5’41"W), área setentrional das várzeas do rio Ivinhema

- Período: 07/072005 a 07/072006

1.11. PROJETO MONITORAMENTO ARQUEOLÓGICO NA MARGEM DIREITA DO RESERVATÓRIO DA USINA HIDRELÉTRICA ENG. SÉRGIO MOTTA (PORTO PRIMAVERA)

- Contrato: CESP/ FAPEC

- Coordenação:Emília M. Kashimoto-UCDB/UFMS e Gilson R. Martins UFMS

- Área pesquisada: entre as coord. geog. $22^{\circ} 24^{\prime} 00^{\prime \prime} \mathrm{S} / 52^{\circ} 58^{\prime} 00^{\prime \prime} \mathrm{W}$ e $20^{\circ} 47^{\prime} 27^{\prime \prime S ~ / ~} 51^{\circ} 37^{\prime} 58$ "W

- Período: 05/12/2003 a 04/12/2005 
1.12. PROJETO LEVANTAMENTO, MONITORAMENTO E RESGATE ARQUEOLÓGICO NA MARGEM DIREITA DOS RESERVATÓRIOS DAS USINAS HIDRELÉTRICAS ENG. SÉRGIO MOTTA, JUPIÁ E ILHA SOLTEIRA - ALTO CURSO DO RIO PARANÁ

- Contrato: CESP/FAPEC

- Coordenação: Emília M. Kashimoto-UFMS e Gilson R. Martins - UFMS

- Período: 01/11/2007 a 01/11/2009

1.13. PROJETO INTEGRADO DE PESQUISA - ARQUEOLOGIA DO ALTO CURSO DO RIO PARANÁ, MS, ENTRE 4.000 A.P. E O SÉCULO XVII: ARTEFATOS E CENÁRIOS CULTURAIS (BOLSAS DE PRODUTIVIDADE EM PESQUISA DO CNPq)

- Processo: CNPq no 350247/2003-0

- Coordenadora bolsista: Emília M. Kashimoto - UCDB/UFMS

- Pesquisador bolsista: Gilson R. Martins - UFMS/CPAQ/DHI/LPA

- Período: 01/08/2003 a 30/07/2006

1.14. PROJETO: OS CAÇADORES-COLETORES NA PRÉ-HISTÓRIA DO ALTO PARANÁ, BRASILÂNDIA/MS: ESCAVAÇÕES ARQUEOLÓGICAS PARA ANÁLISE DA TECNOLOGIA LÍTICA E PALEOAMBIENTE LOCAL

- Termo de Outorga: FUNDECT-MS/UFMS nº 045/06

- Coordenação: Emília M. Kashimoto - UFMS

- Pesquisador adjunto: Gilson R. Martins - UFMS

- Sítios pesquisados na margem direita do rio Paraná: Sítio Brasilândia 8 (Coord. UTM E410808 S7648859) e Sítio Alto Paraná 53 (Coord. UTM E409924 S7648025)

- Período: 08/06/2006 a 08/06/2008

1.15. PROJETO LEVANTAMENTO ARQUEOLÓGICO NAS MARGENS DO ALTO PARANÁ/RIO SUCURIÚ: ANÁLISE DAS FRONTEIRAS CULTURAIS PRÉ-COLONIAIS 
- Termo de Outorga: FUNDECT-MS/UFMS nº 092/06

- Coordenação: Gilson R. Martins - UFMS

- Pesquisadora adjunta: Emília M. Kashimoto - UFMS

- Área pesquisada: entre as coord. geog. $20^{\circ} 47^{\prime} \mathrm{S} / 51^{\circ} 37^{\prime} \mathrm{W}$ e $20^{\circ} 00^{\prime} \mathrm{S} /$ $51^{\circ} 00^{\prime} \mathrm{W}$

- Período: 23/06/2006 a 23/06/2008

1.16. PROJETO: LEVANTAMENTO ARQUEOLÓGICO SISTEMÁTICO AO LONGO DAS ESTRADAS DA PORÇÃO SETENTRIONAL DO PLANALTO SUL-MATO-GROSSENSE: CONTRIBUIÇÃO À ARQUEOLOGIA DA BACIA DO PARANÁ

- Processo:CNPq nº. 400555/2007-7

- Coordenação: Emília M. Kashimoto - UFMS

- Pesquisador adjunto: Gilson R. Martins-UFMS

- Área pesquisada: Nordeste de MS, seccionado pelas rodovias: BR-163, BR-262, BR-267, BR-060, BR-306, MS-215, MS-217, MS-429, MS-142, MS-306, ME-357, MS-324, MS-320, MS-240, MS-377, MS-112, MS-357, MS-338.

- Período: 01/08/2007 a 31/07/2009

1.17. PROJETO: LEVANTAMENTO DAS FRONTEIRAS ARQUEOLÓGICAS TUPIGUARANI NA PORÇÃO MERIDIONAL DO PLANALTO SUL-MATOGROSSENSE

- Processo: CNPq nº. 400697/2008-4

- Coordenação: Emília M. Kashimoto - UFMS

- Área pesquisada: porção meridional do planalto sul-mato-grossense, seccionada pelas rodovias: BR-262, MS-040, MS-357, MS-456, MS338, MS-452, MS-453, MS-459, MS-320, MS-464, MS-134, BR-163, MS455, MS-466, BR-267, MS-145, MS-141, MS-473, MS-276, MS-274, MS469, MS-274, MS-470 e MS-379.

- Período: 2008 a 2010 
1.18. PROJETO INTEGRADO DE PESQUISA - O POVOAMENTO PRÉCOLONIAL NO PLANALTO E PLANÍCIE DA BACIA DO ALTO PARANÁ, MS: PESQUISA ARQUEOLÓGICA E DIVULGAÇÃO CIENTÍFICA (BOLSAS DE PRODUTIVIDADE EM PESQUISA DO CNPq)

- Processo: CNPq no 301072/2006-0

- Coordenadora bolsista: Emília M. Kashimoto - UFMS/MuArq

- Pesquisador bolsista: Gilson R. Martins-UFMS

- Período: 01/03/2007 a 28/02/2010

\section{Projetos de Divulgação Científica}

2.1. PROJETO GERENCIAMENTO DE RECURSOS CULTURAIS: CURADORIA E DIVULGAÇÃO DO ACERVO ARQUEOLÓGICO COLETADO EM ÁREAS IMPACTADAS PELO GASODUTO BOLÍVIA-BRASIL EM MATO GROSSO DO SUL

- Processo: CNPq/ CTPETRO no 468541/00-4

- Coordenação: Gilson R. Martins - UFMS

- Pesquisadora adjunta: Emília M. Kashimoto - UCDB

- Período: 2001

2.2. PROJETO PRODUÇÃO DE MATERIAL DE DIVULGAÇÃO CIENTÍFICA REFERENTE AO PROJETO "ARQUEOLOGIA DO ALTO CURSO DO RIO PARANÁ, MS, ENTRE 4.000 A.P. E O SÉCULO XVII: ARTEFATOS E CENÁRIOS CULTURAIS"

- Processo: CNPq no 402689/2003-8

- Coordenação: Gilson R. Martins - UFMS

- Pesquisadora adjunta: Emília M. Kashimoto - UCDB/UFMS

- Período: 2004 a 2005 